\title{
Research Paper: The Effectiveness of Online Dialogic Storytelling on Vocabulary Skills of Hard of Hearing Children
}

\author{
Farzane Rezaiyan' $^{1}$ Guita Movallali $^{2 *}$ (D), Narges Adibsereshki², Enayatollah Bakhshi ${ }^{3}$ id
}

1. Student Research Committee, University of Social Welfare and Rehabilitation Sciences, Tehran, Iran.

2. Pediatric Neurorehabilitation Research Center, University of Social Welfare and Rehabilitation Sciences, Tehran, Iran

3. Department of Biostatistics, University of Social Welfare and Rehabilitation Sciences, Tehran, Iran.

\begin{tabular}{|c|c|}
\hline $\begin{array}{l}\text { Use your device to scan } \\
\text { and read the article online }\end{array}$ & Dezaivan F, Movallali G, Adibsereshki N, Bakhshi E. The Effectiveness of Online Dialogic Storytelling on Vo- \\
\hline 口iftip: & $\begin{array}{l}\text { cabulary Skills of Hard of Hearing Children Iranian Rehabilitation Journal. 2020; 18(3):319-328. http://dx.doi.org/10.32598/ } \\
\text { irj.18.3.949.1 }\end{array}$ \\
\hline 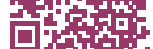 & doi'http://dx.doi.org/10.32598/irj.18.3.949.1 \\
\hline
\end{tabular}

\section{(i) (8)}

Article info:

Received: 07 Sep 2019

Accepted: 02 Nov 2019

Available Online: 01 Sep 2020

\section{Keywords:}

Dialogic storytelling, Hard of hearing, Vocabulary skills, Online storytelling

\section{ABSTRACT}

Objectives: The present study aimed to investigate the effectiveness of an online dialogic storytelling program on vocabulary skills (picture, relative, and oral vocabulary skills) of hard of hearing children.

Methods: In this experimental study with pre-test-post-test and a control group design, 34 mothers of hard of hearing children participated. Children's ages range from 4 to 6 years and they were selected from aural rehabilitation centers in Tehran. They were assigned randomly into the experimental $(\mathrm{n}=17)$ and control $(\mathrm{n}=17)$ groups that were matched for age and sex. Before starting the online dialogic storytelling program, the children took the Test Of Language Development (TOLD-P: 3 ). The online dialogic storytelling was done 20 minutes a day, 3 days a week for 12 weeks for mothers and their children. After completion of the program, the language development test was administered to both groups as the post-test. The data were analyzed by 1-way Analysis of Covariance (ANCOVA).

Results: The results showed that the vocabulary skills, picture, relative and oral vocabulary of the experimental group significantly improved after participating in the online dialogic storytelling sessions $(\mathrm{P}<0.001)$

Discussion: Storytelling is one of the most effective ways to improve the vocabulary skills of hearing-impaired children and it seems that storytelling needs to be included in their rehabilitation programs.

\section{* Corresponding Author:}




\section{Highlights}

- Hard of hearing children often struggle with incidental learning and require vocabulary intervention to increase their lexicon.

- An effective vocabulary intervention is a dialogic storytelling.

- During dialogic storytelling, the adult and child use the book as a shared referent, engaged in the PEER (prompt, evaluate, expand, repeat) cycle using the CROWD (completion, recall, open-ended questions, Wh-prompt, and distancing) question prompts, and focus on the pictures.

\section{Plain Language Summary}

Vocabulary delay is one of the most difficult problems that children with hearing loss face during language acquisition. So treating these problems should be considered in deaf and hard of hearing children. Many previous studies have examined the dialogic storytelling program. The results of this study showed that online dialogic storytelling can improve vocabulary problems in a given group. Parent-child interactions of high quality and the use of pictorial materials are likely the key success factors in the program.

\section{Introduction}

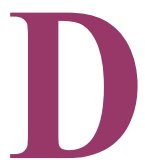

eaf and Hard of Hearing $(\mathrm{D} / \mathrm{HH})$ children are one of the largest groups of children with special needs [1]. The average annual birth rate of infants born with hearing disabilities across the world is estimated as 1 to 3 children out of every 1000 [2]. Language development in $\mathrm{D} / \mathrm{HH}$ children occurs very slowly [3] and the absence of vocabulary (i.e. lexical) skills is taken into account as one of the problems faced by these children while learning a language [4]. For example, a comprehensive study investigating vocabulary skills in $\mathrm{D} / \mathrm{HH}$ children aged 4.5 to 18 years reported that average vocabulary skills in these individuals were similar to those in children at the age of 5-7 years [5]. The results of a review study [6] also demonstrated that only 10 studies had adopted interventions on vocabulary skills in $\mathrm{D} / \mathrm{HH}$ children, and no more than 2 studies had shed light on learning vocabulary [7, 8]. Since 2010 , there has been a rising trend in the number of intervention studies [9-11], but most of these investigations have been performed on individuals in the age group of 8 to 12 years $[7,8,10$, 11]. Although intervention is important for older $\mathrm{D} / \mathrm{HH}$ children, it is better to start lexical interventions sooner $[12,13]$ because vocabulary knowledge can predict later advances in the language [14], literary [15], and reading skills in children $[4,16,17]$. Numerous studies have further revealed that positive family environments and parental involvement in the education of $\mathrm{D} / \mathrm{HH}$ children can be associated with numerous aspects of the develop- ment of words and speech $[18,19]$. D/HH children have problems with vocabulary learning because of their limited opportunities for incidental learning of vocabulary [20], few linguistic interactions with adults [21], reduced interactions while reading books at home because of communication difficulties [22], and parents' tendency towards underestimating linguistic abilities and needs of $\mathrm{D} / \mathrm{HH}$ children [21]. Such individuals usually need more direct educational strategies to increase their vocabulary knowledge [20].

Dialogic Storytelling (DS) has been thus recognized as one of the significant strategies for enhancing vocabulary learning in children since it provides numerous opportunities for learning new words through rich linguistic interactions and conversations using familiar contexts $[23$, 24]. Besides, words are broadened during DS as parents discuss new vocabulary with their children [25]. For the first time, DS was introduced by Whitehurst [26]. The instructions for DS are based on the theory that children learn language skills through practice and feedback with the help of adults that act as scaffolds in their interactions with them $[27,28]$. In other words, DS exploits mediated learning through a person with more knowledge and familiar background to create much more complex conversations and learn new words [27]. The main goals of DS are to encourage active participation, to provide feedback, and to adapt storytelling practices constantly to language development in children [23]. DS can be fulfilled at three levels of introducing new vocabulary, practicing and expanding vocabulary, and linking book contents to children's experiences [29]. All through DS, 
an adult can raise several questions about illustrations or content of a storybook using 5 types of items labeled as CROWD strategy (completion, recall, open-ended questions, Wh-prompt, and distancing) and then, follow a PEER (prompt, evaluate, expand, repeat) sequence in each question in which prompting, evaluating responses by children, and then expanding responses prompted, and finally repeating expanded responses are implemented [26].

Numerous studies have revealed that DS can have a positive impact on vocabulary development in children at risk of hearing loss [30-32] as well as $\mathrm{D} / \mathrm{HH}$ children $[33,34]$. In this respect, Fung's study [34] is one of the few investigations examining the effects of DS based on the development of receptive vocabulary skills in $\mathrm{D} / \mathrm{HH}$ children. In this study, $28 \mathrm{D} / \mathrm{HH}$ children and their mothers participated in an intervention program for 8 weeks with a pre-test and post-test, which consisted of three groups: DS, typical, and control. Then, the parents fulfilled DS using items of CROWD strategy attached to the storybook as well as a series of picture cards. The results of the study showed that the post-test scores of receptive vocabulary skills in the DS group were higher than those in other groups. Also, Trussell conducted a case study involving a teacher and 6 pre-school D/HH students using DS through raising questions in the CROWD strategy about the story and following the PEER sequence. The results of this study revealed the positive effect of storytelling based on expressive vocabulary skills as well as an understanding of the meanings of the words in the context of the story [33].

Nowadays, DS continues its growth path through distance education via electronic books (e-books) [35] since such books endowed with interactive touch screens can provide the possibility of building and strengthening parent-child interactions, teaching DS techniques [36] for all families with different socioeconomic statuses [37], making changes in story backgrounds and magnify pictures as well as using animations and sound effects for better understanding of complex and abstract words (e.g. the concept of flying can be displayed better in a movie format rather than a still image) and reading stories by narrators [38-40]. To minimize differences in opportunities for delayed language learning in children in low-income families, they should have access to touch screens [41] because distance education can lead to high levels of satisfaction in family and children and also provide high-quality services, at low costs across the world [35] . In this study, we aimed to investigate the effectiveness of an online dialogic storytelling program on the vocabulary skills of deaf or hard of hearing children.

\section{Methods}

In this experimental study with pre-test and post-test design and a control group, 34 mothers of hard of hearing children participated. The study population included all children aged 4 to 6 years (Mean \pm SD age: $5.37 \pm 1.03$ years) referring to Family and D/HH Children Centers in the city of Tehran, Iran, in 2018-2019. The study sample was 17 children in each group using convenience sampling methods concerning inclusion criteria $(\mathrm{D} / \mathrm{HH}$ children with hearing aids or cochlear implants, use of spoken language, hearing parents, Persian-speaking parents and children) and exclusion criteria (physical disorders, loss of motor skills, severe vision problems, lack of parent-child involvement in the intervention program for more than two weeks, participation in programs similar to the one implemented in this study) and based on a sample size formula with $80 \%$ test power and $5 \%$ test error. Considering the probability of sample loss, 17 individuals were selected for each group and thus a total of 34 children.

To measure vocabulary skills, we used the modified version (the third edition) of TOLD test (The test of language development-primary, TOLD-P:3). This test was developed by Newcomer and Hamill in 1977 to assess language development in English-speaking children in the United States [42]. This test was also standardized by Hasanzadeh and Minaii (2001) and was initially translated into Persian and then adapted to Persian culture. Checking it qualitatively, this test was administered preexperimentally, experimentally, and finally on 1235 preschool and elementary school children (4 years up to 8 years and 11 months old) in the city of Tehran, Iran. The reliability of this test was confirmed using the internal consistency method and the Cronbach alpha coefficient of 0.98 . This test comprised 9 subtests (6 main subtests and 3 supplementary ones). The main subtests include picture vocabulary, relative vocabulary, oral vocabulary, grammatical understanding, sentence imitation, and grammatical completion. The supplementary subtests also contain word discrimination, phonemic analysis, and word articulation. In this study, three main subtests of picture vocabulary, relative vocabulary, and oral vocabulary measuring lexical skills were employed [43].

\section{Study procedure}

Upon obtaining the approval by the Ethics Committee of the University of Social Welfare and Rehabilitation Sciences and before launching the study, it was registered with the ethical code of IR.USWR.REC.1396.399. After receiving the permit from the University of Social Wel- 
Table 1. Contents of dialogic storytelling sessions

\begin{tabular}{|c|c|c|c|}
\hline Sessions & Objectives & Storybooks & Activities \\
\hline $\begin{array}{l}\text { Weeks } \\
\text { 1-6 } \\
\text { Level one }\end{array}$ & $\begin{array}{l}\text { Introducing new } \\
\text { vocabulary }\end{array}$ & $\begin{array}{l}\text { Rosie's walk (by Pat Hutchins) } \\
\text { Good thing you're not an octopus! (by Julie } \\
\text { Markes, Maggie Smith) } \\
\text { Lizzy and Skunk (by Marie-Louise Fitzpatrick) } \\
\text { Ready for anything! (by Keiko Kasza) } \\
\text { Kisses for daddy (by Frances Watts) } \\
\text { Frog finds a friend (by Max Velthuijs) }\end{array}$ & $\begin{array}{l}\text { Asking wh-questions; e.g. What is this? What is he/ } \\
\text { she saying? } \\
\text { Following responses to questions; e.g. so What color } \\
\text { is that? What is it used for? } \\
\text { Asking children to repeat new words } \\
\text { Helping children if needed } \\
\text { Talking about what children like } \\
\text { Encouraging and admiring children }\end{array}$ \\
\hline $\begin{array}{l}\text { Weeks } \\
7-10 \\
\text { Level two }\end{array}$ & $\begin{array}{l}\text { Practicing and } \\
\text { expanding }\end{array}$ & $\begin{array}{l}\text { Elmer (by David McKee) } \\
\text { Something else (by Kathryn Cave) } \\
\text { Just a minute (by Yuyi Morales) } \\
\text { Grandpa's angel (by Jutta Bauer) }\end{array}$ & $\begin{array}{l}\text { Asking open-ended questions; e.g. What do you see } \\
\text { on this page? Explain more about it? } \\
\text { Following responses by children and expanding them, } \\
\text { as well as adding one or two words to responses pro- } \\
\text { vided by children } \\
\text { Asking children to repeat expanded responses } \\
\text { Helping children if needed } \\
\text { Allowing children to choose a theme and talk about it } \\
\text { Encouraging and admiring children }\end{array}$ \\
\hline $\begin{array}{l}\text { Weeks } \\
\text { 11-12 } \\
\text { Level Three }\end{array}$ & $\begin{array}{l}\text { Associating } \\
\text { story content } \\
\text { with life experi- } \\
\text { ences }\end{array}$ & $\begin{array}{l}\text { How to heal a broken wing (by Bob Graham) } \\
\text { Mr. Postmouse's rounds (by } \\
\text { Marianne Dubuc) }\end{array}$ & $\begin{array}{l}\text { Asking questions about the story plot; e.g. then What } \\
\text { did he/she do? Why was she sad? } \\
\text { Asking questions related to children's personal expe- } \\
\text { riences and past events; e.g. Have you ever seen an } \\
\text { elephant? Have you ever had a teddy bear? } \\
\text { Helping children if needed } \\
\text { Encouraging and admiring children }\end{array}$ \\
\hline
\end{tabular}

Iranian Rehabilitation Dourna

fare and Rehabilitation Sciences to conduct the study and obtaining the letter of introduction to attend Family and D/HH Children centers, several meetings were held with relevant officials and the required information about the purpose and the procedure of the study were presented. Then, the parents signed consent forms regarding their children's participation in the study. All parents with $\mathrm{D} /$ $\mathrm{HH}$ children aged 4 to 6 years referring to the given centers and meeting the inclusion criteria completed demographic characteristics information questionnaires. After that, $34 \mathrm{D} / \mathrm{HH}$ children and their parents were selected. The pre-test was also fulfilled using TOLD-P: 3 to assess lexical skills in these children. After determining the homogeneity of the children based on their age and gender, they were randomized into the experimental and control groups. Next, a one-session educational workshop on DS was held for mothers of $\mathrm{D} / \mathrm{HH}$ children in the experimental group in the form of groups of three and four individuals and then these mothers were added to a channel at Telegram App. After completion of DS sessions, the post-test using TOLD-P: 3 was implemented to assess lexical skills in D/HH children. Finally, the data ob- tained from 34 children were analyzed through statistical methods (2 participants were excluded). To observe ethical principles, mothers in the control group were also added to the given channel following the completion of the intervention sessions. The data obtained before and after the intervention sessions were analyzed using a univariate Analysis of Covariance (ANCOVA).

\section{Dialogic Storytelling (DS)}

Dialogic Storytelling (DS) was conducted online at the Telegram App. For this purpose, mothers of D/HH children in the experimental group were added to a channel at Telegram App, called parent-child storytelling channel. These mothers were required to be online three days a week at certain hours for 12 weeks. Every day, a story along with relevant pictures and videos as well as explanations, questions, and supplementary activities were posted on the channel, and parents were allowed to ask their questions. Finally, they could share images, videos, or audio recordings related to their storytelling and extra activities in the previous session with other members of 
Table 2. Demographic characteristics of groups in terms of age and gender

\begin{tabular}{ccccc}
\hline Variables & Group & 4 Years Old & 5 Years Old & 6 Years Old \\
\hline \multirow{2}{*}{ Age } & Control & 6 & 7 & 4 \\
& Experimental & 6 & 7 & 4 \\
Total & 12 & 14 & Male \\
Group & Female & 10 & 7 & \\
Control & 10 & 7 & Iranian Rehabilitation \ournal
\end{tabular}

Table 3. Descriptive indices of lexical skills in the experimental and control groups

\begin{tabular}{cccc}
\hline \multirow{2}{*}{ Groups } & Variables & \multicolumn{2}{c}{ Mean \pm SD } \\
\cline { 3 - 4 } & & Pre-test & Post-test \\
\hline \multirow{2}{*}{ Control } & Picture vocabulary & $6.06 \pm 1.95$ & $6.29 \pm 1.79$ \\
& Relative vocabulary & $8.53 \pm 2.00$ & $9.29 \pm 1.57$ \\
& Oral vocabulary & $8.59 \pm 1.37$ & $9.12 \pm 1.76$ \\
& Picture vocabulary & $6.35 \pm 1.54$ & $8.82 \pm 1.81$ \\
\hline \multirow{2}{*}{ Experimental } & Relative vocabulary & $9.41 \pm 1.06$ & $12.35 \pm 1.41$ \\
& Oral vocabulary & $9.41 \pm 1.28$ & $11.88 \pm 1.80$ \\
\hline
\end{tabular}

Iranian Rehabilitation Journa

the group. At the end of the session, the list of those present in the session was posted on the channel. It should be noted that parents had time to practice storytelling for their children after each session. In this study, DS was conducted at three levels: at level one, parents introduced new vocabulary; at level two, some new vocabulary was practiced and expanded, and at level three, book content was associated with children's experiences. During storytelling, parents also employed DS using 5 types of items i.e. CROWD strategy to ask questions about the pictures or the content of the storybooks from their children. The questions were as follows (Table 1):

Completion, including filling in blanks (e.g. Elmer was a/an ...elephant)

Recall, comprised of questions in which children needed to remember details about a story or pictures in a book (e.g. What animals told good morning to Elmer?)
Open-ended questions, i.e. questions that had more than one-word responses and there were usually several acceptable responses to these types of questions (e.g. How did Elmer feel?)

Wh-questions, including questions like who, what, where, when, and so on. In these questions, children did not need to remember anything because the response needed to be in the picture of the book in front of them (e.g. Look, what this tree is called?)

Distancing, that is, questions in which children needed to associate the content of a story to their own life experiences (e.g. Elephants played an instrument on Elmer's birthday, what do you do on your birthday?)

Then, each time parents were asking questions from children parents, they were required to follow the PEER sequence, including prompting (parent: What this tree is called?), evaluating responses by children (child: a berry tree, parent: yes), expanding responses (a wild mulberry 
Table 4. Levene's test results for the analysis of homogeneity of variance in the study groups

\begin{tabular}{ccccc}
\hline Variable & F Statistic & df 1 & df 2 & P \\
\hline Picture vocabulary & 0.861 & 1 & 32 & 0.785 \\
\hline Relative vocabulary & 0.754 & 1 & 32 & 0.926 \\
\hline Oral vocabulary & 0.496 & 1 & 32 & 0.576 \\
\hline
\end{tabular}

Table 5. Results of univariate ANCOVA to compare lexical skills in the experimental and control groups

\begin{tabular}{|c|c|c|c|c|c|c|c|}
\hline Variable & Source of Change & Sum of Squares & df & Squared Mean & F Statistic & $\mathbf{P}$ & Effect Size \\
\hline \multirow{2}{*}{ Picture vocabulary } & Pre-test & 56.563 & 1 & 56.563 & 36.964 & 0.00 & 0.544 \\
\hline & Group & 44.901 & 1 & 44.901 & 29.343 & 0.00 & 0.486 \\
\hline \multirow{2}{*}{ Relative vocabulary } & Pre-test & 27.840 & 1 & 27.840 & 19.808 & 0.00 & 0.390 \\
\hline & Group & 50.992 & 1 & 50.992 & 36.279 & 0.00 & 0.539 \\
\hline \multirow{2}{*}{ Oral vocabulary } & Pre-test & 63.266 & 1 & 63.266 & 51.256 & 0.00 & 0.632 \\
\hline & Group & 27.575 & 1 & 27.575 & 22.341 & 0.00 & 0.419 \\
\hline
\end{tabular}

plant), and repeating expanded responses by children (child: a wild mulberry plant). The ultimate goal of DS was that children could tell the story independently. The obtained data were analyzed by 1-way Analysis of Covariance (ANCOVA).

\section{Results}

According to Table 2, both experimental and control groups were homogenized in terms of age and gender. Descriptive indices for vocabulary skills in both experimental and control groups at pre-test and post-test stages are presented in Table 3 .

Table 3 shows descriptive indices of vocabulary skills for the experimental and control groups at the pre-test and post-test stages. Accordingly, it could be concluded that the mean scores at the pre-test and post-test stages in the control group were not changed significantly, but an increase was observed in the post-test scores compared with those in the pre-test stage in the experimental group.

To observe the assumptions of univariate ANCOVA, the normal distribution of the variables was evaluated using the Kolmogorov-Smirnov test. Based on the results and given $\mathrm{P}>0.05$ calculated for all variables, the assumption of a normal distribution of scores was confirmed. To verify the homogeneity of variance, Levene's test was used (Table 4). As shown in Table 4, the assumption of homogeneity of variance for both groups is not significant.

To investigate the study hypothesis i.e. "DS improves vocabulary skills of D/HH children," univariate ANCOVA was employed (Table 5).

Considering the results of univariate ANCOVA, comparing picture, relative, and oral vocabulary skills with the F statistics of 29.343, 36.279, and 22.341, respectively, between the experimental and control groups at the post-test stage, the research hypothesis had been confirmed $(\mathrm{P}<0.001)$. So, involvement in the DS program had led to significant growth in vocabulary skills in $\mathrm{D} /$ $\mathrm{HH}$ children in the experimental group. With respect to the size effect, it could be settled that $49 \%$ of the changes in picture vocabulary, $54 \%$ of variations in relative vocabulary, and $42 \%$ of those in oral vocabulary were due to their involvement in the DS program.

\section{Discussion}

The results of this study revealed that $\mathrm{D} / \mathrm{HH}$ children using an auditory-verbal technique to communicate skills could yield more profits through learning vocabulary via parent-child DS using illustrated e-books. In this study, $\mathrm{D} / \mathrm{HH}$ children in the experimental group in all three lev- 
els of picture, relative, and oral vocabulary skills at the post-test stage were significantly different from those in the control group. The results of this study could also extend the findings by Fung (2005) and Trussell (2018) $[33,34,44]$. The main characteristics of this study were teaching storytelling to parents, practicing storytelling by both parents, using illustrated e-books, setting longer intervention time, and selecting a larger sample size. Numerous studies have further highlighted the importance of parent-child interactive storytelling and have shown that storytelling in a typical way does not fully exploit the potential of parent-child interactions. In other words, the main component facilitating children's vocabulary skills is not mere storytelling, rather it is parent-child interaction that plays a key role in storytelling [33, 45]. Previous research had also demonstrated that $\mathrm{D} / \mathrm{HH}$ children with hearing parents were less likely to communicate with their hearing peers, might use less spontaneous communication, and were less responsive to maternal demands [46]. In a DS program, parents can raise a wide variety of questions and get engaged in interactive activities, in which children not only enjoy the storytelling process but also learn more vocabulary.

Another reason for the effectiveness of DS was the use of illustrated books. Although $\mathrm{D} / \mathrm{HH}$ children have difficulty with spoken language, they can make use of visual methods like hearing children $[47,48]$. D/HH children are often unaware of strategies such as visualizing or imagining to help them understand, so low hearing makes them have a limited semantic understanding [49]. One way to activate the process of understanding and perception which can facilitate inference in children is the use of pictures [33] because they can activate prior knowledge of new words for children and facilitate learning. Thus, children are forced to have mental imagery of data through DS using illustrated books [50]. Accordingly, active processing takes place between the form of the word and its meaning and ultimately a strong link is established between them in memory [51]. A basic strategy that supports vocabulary learning is providing a clear definition along with explanations and examples that can help children better understand the meaning of the words [52]. Moreover, familiar content can be very useful for children [53]. The next factor that may be important for vocabulary learning is providing opportunities for processing words through analysis of complicated words into simple ones which provide the possibility of further learning and better remembering $[54,55]$. Furthermore, practicing and repeating meaningful words is also effective whose effects vary and depend on learning styles, children's abilities, and type of words [56]. Another factor is providing opportunities for children to use words that are being processed and encoded because children should be able to use words to communicate and get feedback from others [57]. Concerning theoretical and practical evidence, parent-child DS regularly exposes children to words, provides opportunities for active word processing and use, focuses on meanings of words in different contexts by expanding children's responses or through explicit definitions of meanings of words, thereby improving lexical skills in D/HH children [58]. Enhancing frequency and quality of storytelling by parents can also have positive effects on lexical skills in such children [59]. It should be noted that the quality of storytelling means that parents have interactions and dialogues with their children in addition to storytelling [60-62] and storytelling techniques need to be taught to parents $[63,64]$. Both parents also need to participate in storytelling, tell the story in their language instead of reading it out, and increase the interest of children in reading books [64]. Besides, parents need to adjust their linguistic inputs to make the concepts included in the book context and maintain children's attention during interactions [61]. Active participation of children during storytelling should also be preserved [65]. Finally, parents should increase the quality of the DS at all levels of storytelling by adding appropriate activities. It should be noted that it is acceptable to work on receptive vocabulary skills for children with limited language skills until expressive ones are ultimately met.

One of the limitations of the present study is the lack of follow-up tests. Therefore, it is suggested that follow-up tests be implemented and multiple methods be used to evaluate vocabulary skills and examine the stability of the effectiveness of dialogic storytelling in future studies in other children with special needs.

\section{Conclusion}

Generally, parent-child DS by combining questions in CROWD strategy through following PEER sequence using illustrated e-books not only encourages children to interact but also promotes the development of vocabulary in $\mathrm{D} / \mathrm{HH}$ children. Such advances in vocabulary skills can thus improve language skills in children in the long term. Given the ease of the practice of DS, educators and parents can use these techniques as a learning method to facilitate vocabulary learning in $\mathrm{D} / \mathrm{HH}$ children. 


\section{Ethical Considerations}

\section{Compliance with ethical guidelines}

The Institutional Review Board of our university approved this study (Code: IR.USWR.REC.1396.399). Informed consent was obtained from all mothers of children for being included in the study.

\section{Funding}

This article was derived from the MA. thesis of the first author, in the Department of Psychology and Education of Exceptional Children, University of Social Welfare and Rehabilitation Sciences.

\section{Authors' contributions}

Developing the study concept, design, and the definition of intellectual content: Farzane Rezaiyan, Guita Movallali; Conducting the study procedures and data collection, searching the literature: Farzane Rezaiyan; Data analysis: Enayatollah Bakhshi and Guita Movallali; Editing: Guita Movallali and Narges Adibsereshki; Reviewing the manuscript and take responsibility for the integrity of the research as a whole from inception to published article: All authors.

\section{Conflict of interest}

The authors declared no conflict of interest.

\section{Acknowledgments}

The researchers hereby express their gratitude to the respected Rehabilitation Centers Principals in the city of Tehran, hard of hearing children, as well as mothers of children participating in the study who contributed to the implementation of this project. A great appreciatation to Faranak Clinic professionals for their help in training dialogic book reading to researchers.

\section{References}

[1] Show RL, Nerbonne MA. Introduction to audiologic rehabilitation. Boston: Allyn and Bacon; 2002.

[2] Baldassari CM, Schmidt C, Schubert CM, Srinivasan P, Dodson KM, Sismanis A. Receptive language outcomes in children after cochlear implantation. OtolaryngologyHead and Neck Surgery. 2009; 140(1):114-9. [DOI:10.1016/j. otohns.2008.09.008] [PMID]
[3] Kretschmer RR, Kretschmer LW, Truax RR. Language development and intervention with the hearing impaired. Pennsylvania: University Park Press; 1978

[4] Harris M, Terlektsi E, Kyle FE. Concurrent and longitudinal predictors of reading for deaf and hearing children in primary school. The Journal of Deaf Studies and Deaf Education. 2017; 22(2):233-42. [DOI:10.1093/deafed/enw101] [PMID]

[5] Moeller MP, Osberger MJ, Eccarius M. Language and learning skills of hearing-impaired students. Receptive language skills. ASHA Monographs. 1986; (23):41-53. [PMID]

[6] Luckner JL, Cooke C. A summary of the vocabulary research with students who are deaf or hard of hearing. American Annals of the Deaf. 2010; 155(1):38-67. [DOI:10.1353/aad.0.0129] [PMID]

[7] Paatsch LE, Blamey PJ, Sarant JZ, Bow CP. The effects of speech production and vocabulary training on different components of spoken language performance. Journal of Deaf Studies and Deaf Education. 2006; 11(1):39-55. [DOI:10.1093/ deafed/enj008] [PMID]

[8] Robiins N. [The effects of syntax an the reading comprehension of hearing impaired children (Japanese)]. The Volta Review. 1981; 83:105-15. https:/ci.nii.ac.jp/ naid/10007698810/

[9] Bowers LM, Schwarz I. Assessing response to basic concept instruction: Preliminary evidence with children who are deaf. Communication Disorders Quarterly. 2013; 34(4):221-31. [DOI:10.1177/1525740112469662]

[10] Dimling LM. Conceptually based vocabulary intervention: Second graders' development of vocabulary words. American Annals of The Deaf. 2010; 155(4):425-48. [DOI:10.1353/ aad.2010.0040] [PMID]

[11] Messier J, Wood C. Facilitating vocabulary acquisition of children with cochlear implants using electronic storybooks. Journal of Deaf Studies and Deaf Education. 2015; 20(4):356-73. [DOI:10.1093/deafed/env031] [PMID]

[12] Moats Lc. Language Essentials for Teachers of Reading and Spelling (LETRS). Frederick, CO: Sopris West. 2005.

[13] Romeo RR, Segaran J, Leonard JA, Robinson ST, West MR, Mackey AP, et al. Language exposure relates to structural neural connectivity in childhood. Journal of Neuroscience. 2018; 38(36):7870-7. [DOI:10.1523/JNEUROSCI.0484-18.2018] [PMID] [PMCID]

[14] Meinzen-Derr J, Wiley S, Grether S, Choo DI. Children with cochlear implants and developmental disabilities: A language skills study with developmentally matched hearing peers Research in Developmental Disabilities. 2011; 32(2):757-67. [DOI:10.1016/j.ridd.2010.11.004] [PMID]

[15] Storch SA, Whitehurst GJ. Oral language and code-related precursors to reading: Evidence from a longitudinal structural model. Developmental Psychology. 2002; 38(6):934-47. [DOI:10.1037/0012-1649.38.6.934] [PMID]

[16] Kyle FE, Harris M. Concurrent correlates and predictors of reading and spelling achievement in deaf and hearing school children. The Journal of Deaf Studies and Deaf Education. 2006; 11(3):273-88. [DOI:10.1093/deafed/enj037] [PMID] 
[17] Kyle FE, Harris M. Predictors of reading development in deaf children: A 3-year longitudinal study. Journal of Experimental Child Psychology. 2010; 107(3):229-43. [DOI:10.1016/j. jecp.2010.04.011] [PMID]

[18] Zevenbergen AA, Whitehurst GJ. Dialogic reading: A shared picture book reading intervention for preschoolers. In: van Kleeck A, Stahl SA, Bauer EB, editors. On Reading Books to Children: Parents and Teachers. Frederick: Sopris West; 2003.

[19] Moeller MP. Early intervention and language development in children who are deaf and hard of hearing. Pediatrics. 2000; 106(3):e43. [DOI:10.1542/peds.106.3.e43] [PMID]

[20] Brackenbury T, Ryan T, Messenheimer T. Incidental word learning in a hearing child of deaf adults. Journal of Deaf Studies and Deaf Education. 2006; 11(1):76-93. [DOI:10.1093/ deafed/enj018] [PMID]

[21] Easterbrooks SR, Baker S. Language learning in children who are deaf and hard of hearing: Multiple Pathways. London: Pearson; 2002. https://books.google.com/ books/about/Language_Learning_in_Children_who_are_ De.html?id=C80KAAAACAAJ

[22] Stobbart C, Alant E. Home-based literacy experiences of severely to profoundly deaf preschoolers and their hearing parents. Journal of Developmental and Physical Disabilities. 2008; 20(2):139-53. [DOI:10.1007/s10882-007-9085-1]

[23] Whitehurst GJ, Falco FL, Lonigan CJ, Fischel JE, DeBaryshe $\mathrm{BD}$, Valdez-Menchaca MC, et al. Accelerating language development through picture book reading. Developmental Psychology. 1988; 24(4):552-9. [DOI:10.1037/0012-1649.24.4.552]

[24] Nelson LH, Stoddard SM, Fryer SL, Muñoz K. Increasing engagement of children who are DHH during parent-child storybook reading. Communication Disorders Quarterly. 2019; 41(1):12-21. [DOI:10.1177/1525740118819662]

[25] Justice LM. Word exposure conditions and preschoolers'novel word learning during shared storybook reading. Reading Psychology. 2002; 23(2):87-106. [DOI:10.108 0/027027102760351016]

[26] Whitehurst GJ, Arnold DS, Epstein JN, Angell AL, Smith $\mathrm{M}$, Fischel JE. A picture book reading intervention in day care and home for children from low-income families. Developmental Psychology. 1994; 30(5):679-89. [DOI:10.1037/00121649.30.5.679]

[27] Vygotsky LS. Mind in society: The development of higher psychological processes. Cambridge: Harvard university press; 1980. [DOI:10.2307/j.ctvjf9vz4]

[28] Bandura A, Walters RH. Social learning theory: Prenticehall Englewood Cliffs, NJ; 1977. http://www.asecib.ase.ro/ $\mathrm{mps} /$ Bandura_SocialLearningTheory.pdf

[29] Flynn KS. Developing children's oral language skills through dialogic reading: Guidelines for implementation. Teaching Exceptional Children. 2011; 44(2):8-16. [DOI:10.117 7/004005991104400201]

[30] Justice LM, Skibbe LE, McGinty AS, Piasta SB, Petrill S. Feasibility, efficacy, and social validity of home-based storybook reading intervention for children with language impairment. Journal of Speech, Language, and Hearing Research. 2011; 54(2):523-38. [DOI:10.1044/1092-4388(2010/09-0151)] [PMID]
[31] Hargrave AC, Sénéchal M. A book reading intervention with preschool children who have limited vocabularies: The benefits of regular reading and dialogic reading. Early Childhood Research Quarterly. 2000; 15(1):75-90. [DOI:10.1016/ S0885-2006(99)00038-1]

[32] van Kleeck A, Vander Woude J, Hammett L. Fostering literal and inferential language skills in Head Start preschoolers with language impairment using scripted book-sharing discussions. American Journal of Speech-Language Pathology. 2006; 15(1):85-95. [DOI:10.1044/1058-0360(2006/009)] [PMID]

[33] Trussell JW, Hasko J, Kane J, Amari B, Brusehaber A. Interactive storybook reading instruction for preschoolers who are deaf and hard of hearing: A multiple probe across behaviors analysis. Language, Speech, and Hearing Services in Schools. 2018; 49(4):922-37. [DOI:10.1044/2018_LSHSS-17-0085] [PMID]

[34] Fung PC, Chow BWY, McBride-Chang C. The impact of a dialogic reading program on deaf and hard-of-hearing kindergarten and early primary school-aged students in Hong Kong. Journal of Deaf Studies and Deaf Education. 2005; 10(1):82-95. [DOI:10.1093/deafed/eni005] [PMID]

[35] Blaiser KM, Behl D, Callow-Heusser C, White KR. Measuring costs and outcomes of tele-intervention when serving families of children who are deaf/hard-of-hearing. International Journal of Telerehabilitation. 2013; 5(2):3-10. [DOI:10.5195/ IJT.2013.6129] [PMID] [PMCID]

[36] Korat O, Or T. How new technology influences parentchild interaction: The case of e-book reading. First Language. 2010; 30(2):139-54. [DOI:10.1177/0142723709359242]

[37] Troseth GL, Strouse GA, Flores I, Stuckelman ZD, Johnson CR. An enhanced eBook facilitates parent-child talk during shared reading by families of low socioeconomic status. Early Childhood Research Quarterly. 2020; 50:45-58 [DOI:10.1016/j. ecresq.2019.02.009]

[38] Smeets DJ, Bus AG. The interactive animated e-book as a word learning device for kindergartners. Applied Psycholinguistics. 2015;36(4):899-920. [DOI:10.1017/S0142716413000556]

[39] Takacs ZK, Swart EK, Bus AG. Benefits and pitfalls of multimedia and interactive features in technology-enhanced storybooks: A meta-analysis. Review of Educational Research 2015; 85(4):698-739. [DOI:10.3102/0034654314566989] [PMID] [PMCID]

[40] Richter A, Courage ML. Comparing electronic and paper storybooks for preschoolers: Attention, engagement, and recall. Journal of Applied Developmental Psychology. 2017; 48:92-102. [DOI:10.1016/j.appdev.2017.01.002]

[41] Carter PL, Welner KG. Closing the opportunity gap: What America must do to give every child an even chance.Oxford: Oxford University Press; 2013. [DOI:10.1093/acprof:o so/9780199982981.001.0001]

[42] Newcomer P, Hammill D. Test of Language DevelopmentPrimary. Austin, TX: PRO-ED. Inc; 1997. https:/ / www.worldcat.org/title/told-p3-test-of-language-development-primary/ oclc/37320876

[43] Hasanzadeh S, Minaei A. [Adaptation and normalization of language development test TOLD-P: 3 for Persian-speaking children of Tehran: Part 2 (Persian)]. Research Exceptional Children. 2002; 1(2):119-34. http://joec.ir/article-1-505-en. html 
[44] Trussell JW, Dunagan J, Kane J, Cascioli T. The effects of interactive storybook reading with preschoolers who are deaf and hard-of-hearing. Topics in Early Childhood Special Education. 2017; 37(3):147-63. [DOI:10.1177/0271121417720015]

[45] Wauters L, Dirks E. Interactive reading with young deaf and hard-of-hearing children in eBooks versus print books. The Journal of Deaf Studies and Deaf Education. 2017; 22(2):243-52. [DOI:10.1093/deafed/enw097] [PMID]

[46] Henggeler SW, Cooper PF. Deaf child-hearing mother interaction: Extensiveness and reciprocity. Journal of Pediatric Psychology. 1983; 8(1):83-95. [DOI:10.1093/jpepsy/8.1.83] [PMID]

[47] Musselman C. How do children who can't hear learn to read an alphabetic script? A review of the literature on reading and deafness. Journal of Deaf Studies and Deaf Education. 2000; 5(1):9-31. [DOI:10.1093/deafed/5.1.9] [PMID]

[48] Jimenez SR, Saylor MM. Preschoolers' word learning and story comprehension during shared book reading. Cognitive Development. 2017; 44:57-68. [DOI:10.1016/j. cogdev.2017.08.011]

[49] Paul PV. Literacy and deafness: The development of reading, writing, and literate thought. Boston: Allyn and Bacon; 1998.

[50] Bus AG, Van Ijzendoorn MH, Pellegrini AD. Joint book reading makes for success in learning to read: A meta-analysis on intergenerational transmission of literacy. Review of Educational Research. 1995; 65(1):1-21 [DOI:10.3102/00346543065001001]

[51] Akhtar N, Jipson J, Callanan MA. Learning words through overhearing. Child Development. 2001; 72(2):416-30. [DOI:10.1111/1467-8624.00287] [PMID]

[52] McKeown MG, Beck IL. Effects of vocabulary instruction on measures of language processing: Comparing two approaches. Early Childhood Research Quarterly. 2014 29(4):520-30. [DOI:10.1016/j.ecresq.2014.06.002]

[53] Pashler H, Bain PM, Bottge BA, Graesser A, Koedinger K, McDaniel M, et al. Organizing instruction and study to improve student learning. IES practice guide. NCER 2007-2004 Washington: National Center for Education Research; 2007. [DOI:10.1037/e607972011-001]

[54] Clay MM. Record of oral language: Observing changes in the acquisition of language structures: A guide for teaching. Portsmouth: Heinemann Education; 2015. https:// files.eric. ed.gov/fulltext/ED498555.pdf

[55] Goldin-Meadow S, Levine SC, Hedges LV, Huttenlocher J, Raudenbush SW, Small SL. New evidence about language and cognitive development based on a longitudinal study: Hypotheses for intervention. American Psychologist. 2014; 69(6):588-99. [DOI:10.1037/a0036886] [PMID] [PMCID]

[56] McGregor KK, Sheng L, Ball T. Complexities of expressive word learning over time. Language, Speech, and Hearing Services in Schools. 2007; 38(4):353-64. [DOI:10.1044/01611461(2007/037)] [PMID] [PMCID]

[57] Tamis-LeMonda CS, Kuchirko Y, Song L. Why is infant language learning facilitated by parental responsiveness? Current Directions in Psychological Science. 2014; 23(2):121-6. [DOI:10.1177/0963721414522813]
[58] Justice LM, Meier J, Walpole S. Learning new words from storybooks: An efficacy study with at-risk kindergartners. Language, Speech, and Hearing Services in Schools. 2005; 36(1):17-32. [DOI:10.1044/0161-1461(2005/003)] [PMID]

[59] Mol SE, Bus AG, De Jong MT, Smeets DJ. Added value of dialogic parent-child book readings: A meta-analysis. Early Education and Development. 2008; 19(1):7-26. [DOI:10.1080/10409280701838603]

[60] Barnes EM, Dickinson DK. The impact of teachers' commenting strategies on children's vocabulary growth. Exceptionality. 2017; 25(3):186-206. [DOI:10.1080/09362835.2016.1196447]

[61] DesJardin JL, Stika CJ, Eisenberg LS, Johnson KC, Ganguly DMH, Henning SC, et al. A longitudinal investigation of the home literacy environment and shared book reading in young children with hearing loss. Ear and Hearing. 2017; 38(4):441-54. [DOI:10.1097/AUD.0000000000000414] [PMID] [PMCID]

[62] Tompkins V, Bengochea A, Nicol S, Justice LM. Maternal inferential input and children's language skills. Reading Research Quarterly. 2017; 52(4):397-416. [DOI:10.1002/rrq.176]

[63] Deckner DF, Adamson LB, Bakeman R. Child and maternal contributions to shared reading: Effects on language and literacy development. Journal of Applied Developmental Psychology. 2006; 27(1):31-41. [DOI:10.1016/j.appdev.2005.12.001]

[64] Malin JL, Cabrera NJ, Rowe ML. Low-income minority mothers' and fathers' reading and children's interest: Longitudinal contributions to children's receptive vocabulary skills. Early Childhood Research Quarterly. 2014; 29(4):425-32. [DOI:10.1016/j.ecresq.2014.04.010] [PMID] [PMCID]

[65] Trivette CM, Dunst CJ, Gorman E. Effects of parent-mediated joint book reading on the early language development of toddlers and preschoolers. Center for Early Literacy Learning. 2010; 3(2):1-15. http://www.earlyliteracylearning.org/ cellreviews/cellreviews_v3_n2.pdf 